\title{
PENINGKATAN KESADARAN LINGKUNGAN BAGI PENGURUS ORGANISASI SISWA INTRA-SEKOLAH: PEMBUATAN PUPUK ORGANIK CAIR DARI LIMBAH
}

\author{
Renna Eliana Warjoto ${ }^{1}$ dan Tati Barus \\ ${ }^{1}$ Fakultas Teknobiologi, Universitas Katolik Indonesia Atma Jaya, Jalan Jendral Sudirman no 51, Jakarta 12930 \\ Email: renna.eliana@atmajaya.ac.id
}

\begin{abstract}
The waste problem in Indonesia has not yet been entirely resolved. The biggest challenge is the lack of waste management awareness in various walks of life. Therefore, we should start the environmental education and waste management awareness as early as possible in families and schools. This activity aimed to train senior high school students, especially the student organization boards, to recycle organic waste into liquid organic fertilizer. The student organization boards are leadership figures at the school. Therefore, through this activity, they were expected to set a good example for other students related to organic waste management and valorization at school. The activity was initiated by an interactive lecture, continued by a liquid organic fertilizer processing workshop and an interactive discussion. At the time of the harvest, one group of participants succeeded in producing liquid organic fertilizer without a foul odor. In general, the participating students stated that liquid organic fertilizer was reasonably easy to produce even though it was not as simple as composting. For future attempts, the combination of activities including organic waste conversion into liquid organic fertilizer or compost and inorganic waste processing into handicraft creations will be more interesting for students. In the long-term point of view, the awareness of the high school students in organic as well as inorganic waste management is expected to increase and becomes a positive impact on the broader environment and communities.
\end{abstract}

Keywords: environmental awareness, liquid organic fertilizer, organic waste, student organization.

\begin{abstract}
ABSTRAK
Persoalan sampah di Indonesia belum sepenuhnya terselesaikan. Tantangan terbesar adalah kurangnya kesadaran tentang pengelolaan sampah di berbagai lapisan masyarakat. Oleh karena itu, kita perlu memulai pendidikan lingkungan dan kesadaran tentang pengelolaan sampah sedini mungkin dalam keluarga dan sekolah-sekolah. Kegiatan ini bertujuan melatih siswa sekolah menengah atas (SMA), khususnya para pengurus Organisasi Siswa Intrasekolah (OSIS) untuk mendaur ulang sampah organik menjadi pupuk organik cair (POC). Para pengurus OSIS adalah figur siswa yang menjadi pemimpin organisasi di sekolah. Oleh karena itu, melalui kegiatan ini diharapkan mereka dapat menjadi contoh atau teladan yang baik bagi siswa lainnya dalam pengelolaan dan pemanfaatan sampah organik di lingkungan sekolah. Kegiatan ini diawali dengan ceramah interaktif yang kemudian dilanjutkan dengan lokakarya pembuatan POC dan diskusi interaktif. Pada saat panen, satu kelompok peserta berhasil memperoleh POC tanpa bau yang tidak sedap. Secara umum, siswa peserta menyatakan bahwa pembuatan POC cukup mudah dilakukan meskipun tidak sesederhana pembuatan kompos. Untuk kegiatan serupa di masa yang akan datang, kombinasi aktivitas terkait konversi sampah organik menjadi POC dan kompos yang tidak berbau serta pengolahan sampah anorganik menjadi aneka kreasi kerajinan tangan akan lebih menarik bagi para siswa. Dalam jangka panjang, diharapkan kesadaran para siswa dalam mengolah dan memanfaatkan kembali sampah organik maupun anorganik dapat meningkat dan menjadi dampak positif bagi lingkungan masyarakat yang lebih luas.
\end{abstract}

Kata Kunci: kesadaran lingkungan, OSIS, pupuk organik cair, sampah organik.

\section{PENDAHULUAN}

Salah satu masalah yang masih dihadapi Indonesia dan belum dapat tertangani secara tuntas adalah permasalahan sampah. Penduduk Indonesia yang kian bertambah berimplikasi pada peningkatan karakteristik dan volume sampah. Oleh karena itu, pengelolaan sampah yang tercakup dalam prinsip 3R (Reduce, Reuse, Recycle) perlu dilakukan oleh semua lapisan masyarakat. Pengurangan volume sampah (reduce) dapat dilakukan melalui pemanfaatan barang-barang yang dapat digunakan berkali-kali (reuse), seperti kotak makan, sedotan kaca atau stainless steel, gelas dan piring beling, tas belanja kain, dan lain-lain. Prinsip recycle dapat dimulai melalui pemilahan sampah, yakni antara sampah organik dan anorganik. 
Perkiraan produksi sampah per hari di DKI Jakarta pada tahun 2016 adalah sebesar 7.099,08 $\mathrm{m}^{3}$. Dari sekian banyak sampah yang dihasilkan per hari, hanya sekitar 84,75\% sampah terangkut oleh pemerintah. Dari total volume sampah yang terangkut per hari, lebih dari 50\% merupakan sampah organik $\left(3.233,77 \mathrm{~m}^{3}\right.$ ) (BPS Indonesia, 2017). Jika sampah organik dapat dikelola dengan baik oleh setiap unit masyarakat, maka volume sampah organik yang harus diangkut ke tempat pembuangan akhir (TPA) tentu akan berkurang secara signifikan. Sayangnya di Indonesia masih sangat sedikit warga yang melakukan pemilahan sampah. Di DKI Jakarta hanya sekitar 3,39\% warga yang memilah sampah dan memanfaatkannya, 7,95\% warga memilah sampah lalu dibuang, dan $88,65 \%$ warga membuang sampah tanpa dipilah terlebih dahulu (Garnesia, 2020). Sebenarnya, sampah organik dapat diolah lebih lanjut menjadi kompos dan pupuk organik cair (POC), yang kemudian dapat diaplikasikan untuk memperbaiki kualitas tanah dan bercocok tanam. Sementara itu, sampah anorganik dapat dijual ke bank sampah atau pengepul, ataupun dikreasikan menjadi barang-barang yang bernilai guna.

Berdasarkan Peraturan Menteri Pertanian No. 2 Tahun 2006, pupuk organik adalah pupuk yang sebagian besar atau seluruh bagiannya terdiri dari materi organik yang berasal dari sisa tanaman atau hewan, yang telah mengalami konversi berbentuk padat maupun cair. Pupuk organik mengandung bahan-bahan organik yang dibutuhkan untuk memperbaiki sifat fisik, kimiawi, dan biologis tanah. Sampah organik dapat diolah menjadi kompos maupun POC. Konversi sampah organik menjadi kompos maupun POC dapat dilakukan dengan cara sederhana dalam skala individu maupun rumah tangga. Pengolahan sampah organik menjadi kompos biasanya bersifat aerob atau membutuhkan suplai oksigen (Stabnikova et al., 2005; Warjoto et al., 2018), sehingga relatif tidak berbau, sedangkan pengolahan sampah organik menjadi POC biasanya berlangsung secara anaerob atau semi-aerob. Konsentrat POC yang diperoleh dari hasil pengolahan sampah organik selanjutnya dapat digunakan sebagai bioaktivator untuk pembuatan kompos (Means et al., 2005; Varma \& Kalamdhad, 2014).

Kesadaran masyarakat Indonesia terhadap pentingnya kebersihan lingkungan dan pengelolaan sampah masih sangat rendah. Kepedulian masyarakat untuk bersama-sama menjaga kebersihan lingkungan juga masih cukup memprihatinkan. Hal ini tidak hanya nampak pada kelompok masyarakat dengan tingkat ekonomi menengah ke bawah saja, namun juga menengah ke atas. Seringkali kita melihat sampah dibuang begitu saja ke jalanan dari dalam mobil yang terbilang cukup mewah. Selain itu, inisiatif masyarakat dengan tingkat ekonomi menengah ke atas untuk memilah dan mengelola sampah rumah tangga juga masih rendah. Oleh sebab itu, penyuluhan dan peningkatan kesadaran masyarakat untuk menjaga kebersihan dan mengelola sampah harus dimulai sejak dini, yakni dalam keluarga dan sekolah-sekolah. Kegiatan ini bertujuan untuk melatih siswa Sekolah Menengah Atas (SMA) untuk mendaur ulang sampah organik menjadi POC. Kegiatan dilakukan di SMA Tarakanita 1 Jakarta untuk menanamkan kesadaran lingkungan di kalangan pengurus Organisasi Siswa Intra-Sekolah (OSIS). Pengurus OSIS dapat dikategorikan sebagai pemimpin muda yang mulai melatih pengaruh positif mereka sejak dini di lingkungan sekolah. Melalui kegiatan ini, diharapkan kesadaran untuk mengelola lingkungan dapat disebarkan ke semua siswa. Selain itu, dalam jangka panjang, aktivitas ini diharapkan dapat menjadi cikal bakal kepedulian generasi muda terhadap pengelolaan lingkungan dan memberikan dampak positif bagi masyarakat yang lebih luas.

\section{METODE PELAKSANAAN}

Kegiatan ini diikuti oleh 41 siswa pengurus OSIS yang dibagi ke dalam empat kelompok aktif. Kegiatan diawali dengan ceramah interaktif, lalu diikuti dengan lokakarya atau praktik pembuatan POC dan diskusi interaktif dalam bentuk kuis berhadiah. Tatap muka dengan narasumber kegiatan 
atau tim pengabdi berlangsung selama satu hari. Selanjutnya, tim pengabdi membimbing para siswa peserta melalui diskusi dan online monitoring melalui Whatsapp group hingga POC dipanen.

\section{Ceramah interaktif}

Ceramah interaktif dilakukan untuk mengingatkan peserta tentang pentingnya pengelolaan sampah dan kebersihan lingkungan. Pengenalan istilah POC, teori yang mendasarinya, serta metode pembuatannya juga dipaparkan saat ceramah interaktif. Tim pengabdi yang menjadi narasumber sesekali melemparkan pertanyaan atau meminta peserta untuk memberikan komentar selama ceramah interaktif berlangsung.

\section{Lokakarya pembuatan POC}

Alat yang diperlukan untuk pembuatan POC per kelompok mencakup 1 ember plastik dengan penutup (ukuran $\pm 5 \mathrm{~L}$ ), karung beras atau kantong plastik yang telah diberi banyak lubang (ukuran $\pm 5 \mathrm{~kg})$, gayung (1 buah), tongkat kayu $( \pm 50 \mathrm{~cm})$, sarung tangan karet atau plastik, masker, tali rafia $( \pm 1 \mathrm{~m})$, dan beban/batu bata merah (1 buah). Bahan yang dibutuhkan meliputi limbah sayuran hijau yang telah dirajang atau dipotong kecil-kecil $( \pm 2,5 \mathrm{~kg})$, larutan Effective Microorganisms 4 (EM4) $( \pm 0,2 \mathrm{~L})$, gula pasir ( \pm 1 ons), air bekas cucian beras pertama $( \pm 0,5 \mathrm{~L})$, air kelapa tua ( \pm $0,5 \mathrm{~L})$, dan air bersih sesuai kebutuhan.

Pupuk organik cair (POC) kemudian dibuat secara anaerob atau tidak membutuhkan oksigen. Itulah sebabnya dibutuhkan ember dengan tutup. Larutan media dalam ember dibuat dengan mencampurkan semua bahan (termasuk EM4) selain sampah organik. Sampah sayur yang telah dirajang dimasukkan ke dalam karung beras atau kantong plastik yang telah diberi banyak lubang. Sampah dipadatkan, lalu bagian ujung karung atau kantong diikat dengan tali rafia. Karung atau kantong plastik berisi sampah sayuran kemudian dimasukkan ke dalam larutan media dalam ember. Ember diberi tambahan air sedikit demi sedikit hingga semua bagian sampah organik dalam karung terendam. Media dalam ember diaduk kembali dengan tongkat agar tercampur merata. Beban diletakkan di atas karung atau kantong berisi sampah agar tidak mengapung. Selanjutnya, ember ditutup rapat agar udara dan serangga tidak masuk ke dalam ember. Ember berisi media dan sampah organik disimpan/diinkubasi di tempat yang teduh dan tidak terkena sinar matahari langsung selama 14-21 hari.

\section{Diskusi interaktif}

Setelah pembuatan POC, tim pengabdi memberikan beberapa pertanyaan kepada peserta dalam bentuk kuis berhadiah. Pertanyaan bervariasi untuk mengakomodasi siswa peserta yang berasal dari kelas IPA, IPS, dan Bahasa (Tabel 1).

\section{Tabel 1}

Beberapa Pertanyaan yang Diberikan Kepada Peserta

\begin{tabular}{ll}
\hline Pertanyaan & Keterangan \\
\hline Untuk apa larutan EM4 ditambahkan ke dalam media? & Pertanyaan untuk semua siswa peserta \\
Bakteri menguraikan sampah sayuran dengan bantuan apa? & Pertanyaan khusus untuk siswa IPA \\
$\begin{array}{l}\text { Mengapa sampah sayuran perlu dirajang terlebih dahulu? } \\
\begin{array}{l}\text { Siapa yang dapat menceritakan kembali tahapan pembuatan pupuk } \\
\text { organik cair (POC)? }\end{array}\end{array}$ & $\begin{array}{l}\text { Pertanyaan khusus untuk siswa IPS } \\
\end{array}$ \\
\hline
\end{tabular}

\section{Monitoring dan evaluasi}

Tahap monitoring dilakukan secara online melalui Whatsapp group hingga POC dipanen. Setiap kelompok kemudian diminta untuk mengisi kuesioner online yang berisi evaluasi/hasil 
pengamatan POC dan umpan balik (kesan dan saran) untuk kegiatan. Evaluasi POC saat panen meliputi masa inkubasi (hari), warna POC, aroma POC, dan ada tidaknya bercak putih di permukaan POC.

\section{HASIL DAN PEMBAHASAN}

Selama ceramah interaktif berlangsung, para siswa peserta mengikuti dengan baik dan aktif menjawab setiap pertanyaan yang diberikan tim pengabdi. Para siswa dan tim pengabdi aktif berdiskusi (bertanya-jawab) seputar praktik pembuatan POC (Gambar 1).

\section{Gambar 1}

Diskusi Seputar Praktik Pembuatan Pupuk Organik Cair (POC)

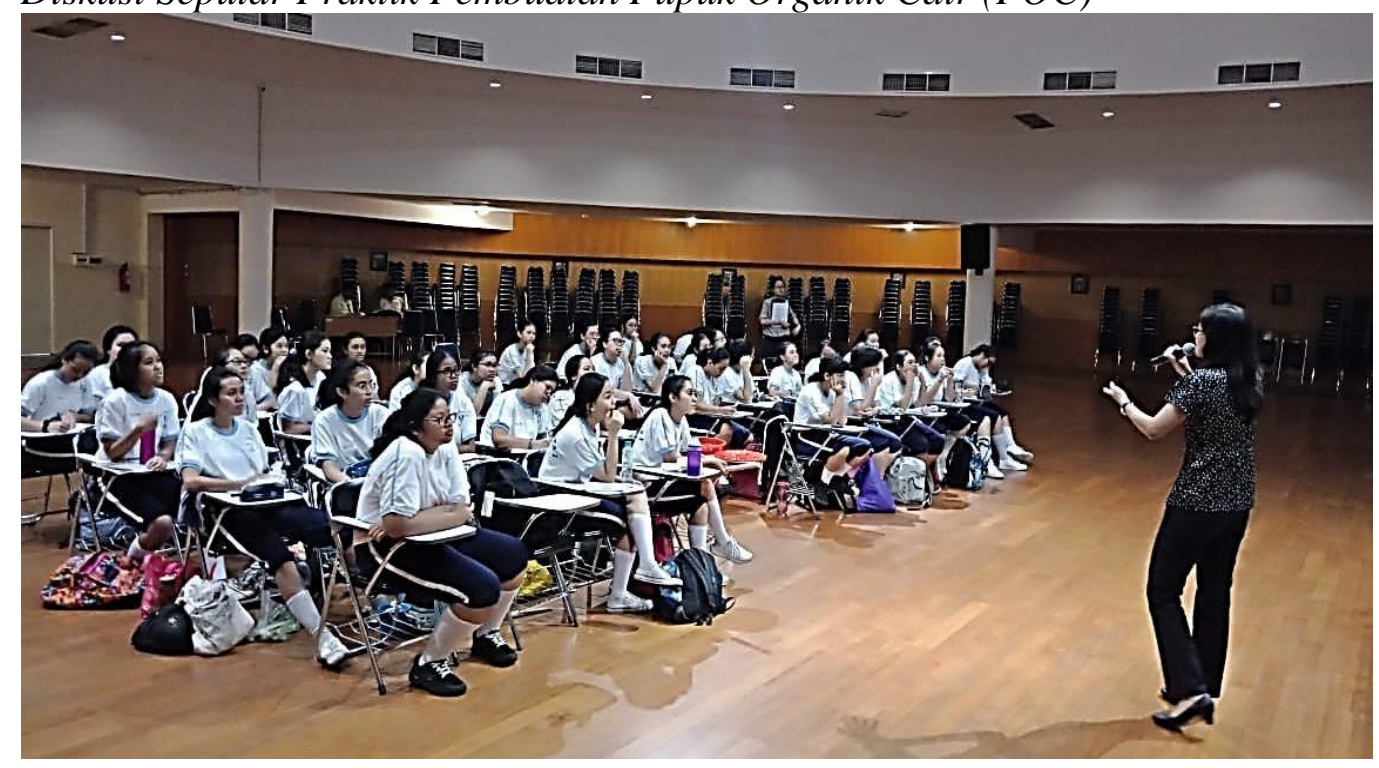

Saat lokakarya pembuatan POC dilakukan, peserta mengikuti setiap langkah dengan baik, mulai dari pembuatan media (Gambar 2), pemotongan sampah sayur yang kemudian dimasukkan ke dalam karung beras atau kantong plastik berlubang (Gambar 3), serta persiapan fermentasi anaerob sampah sayur dalam ember (Gambar 4-6).

\section{Gambar 2}

(a) Siswa Sedang Mencampurkan dan Melarutkan Semua Bahan Media

(b) Tim Pengabdi Membantu Menuangkan Larutan EM4 ke Dalam Media

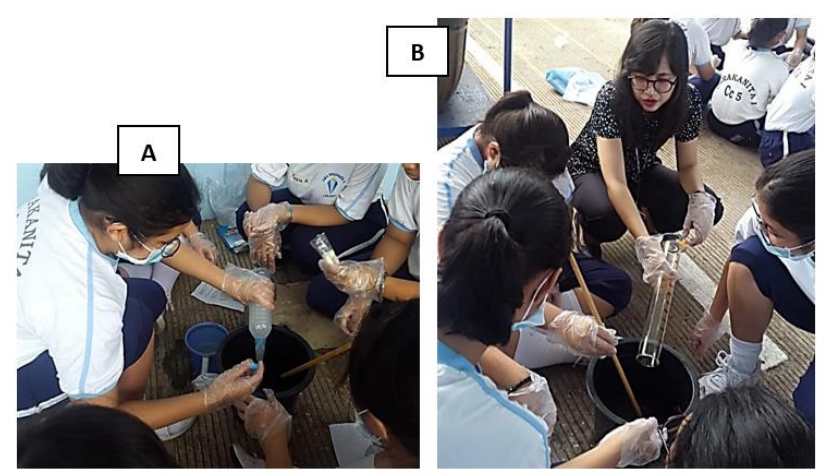

(a)

(b) 


\section{Gambar 3}

Siswa Memasukkan Sampah Sayuran ke dalam Karung, Mengikat Karung, dan Memberi

Tambahan Lubang pada Karung

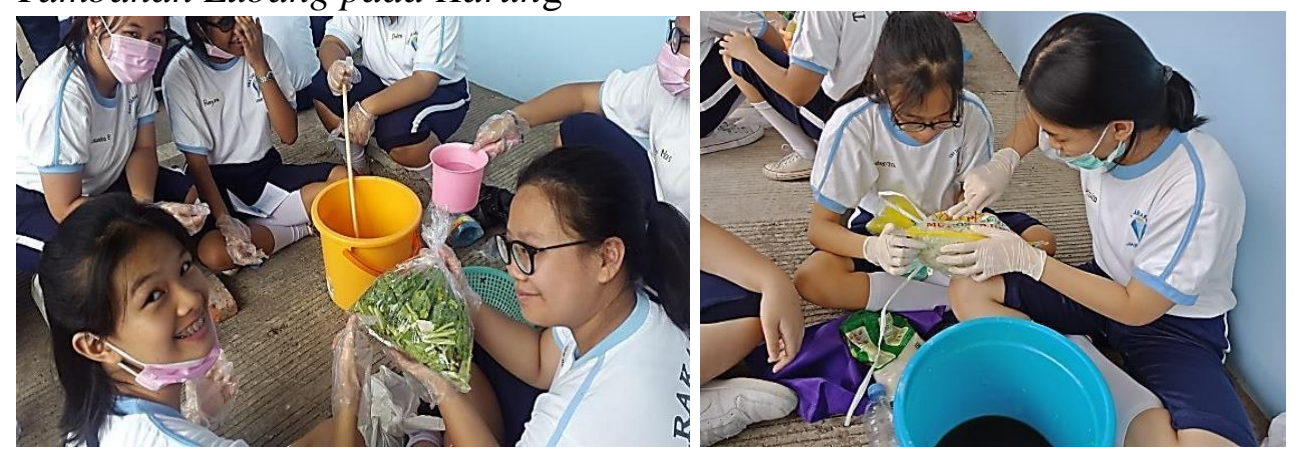

\section{Gambar 4}

Sampah Organik dalam Karung Dimasukkan ke Media dalam Ember

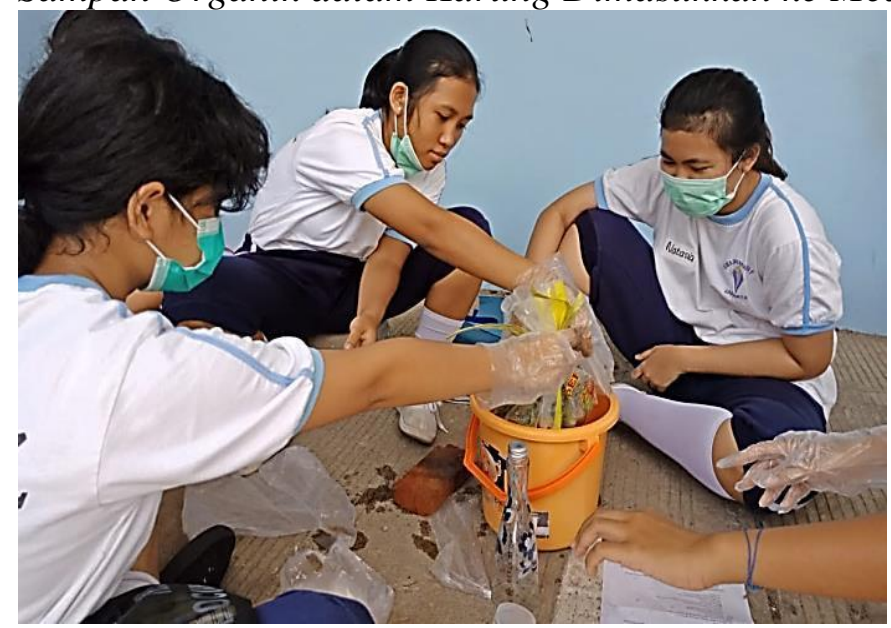

\section{Gambar 5}

Air Ditambahkan ke dalam Ember Agar Sampah Organik Terendam

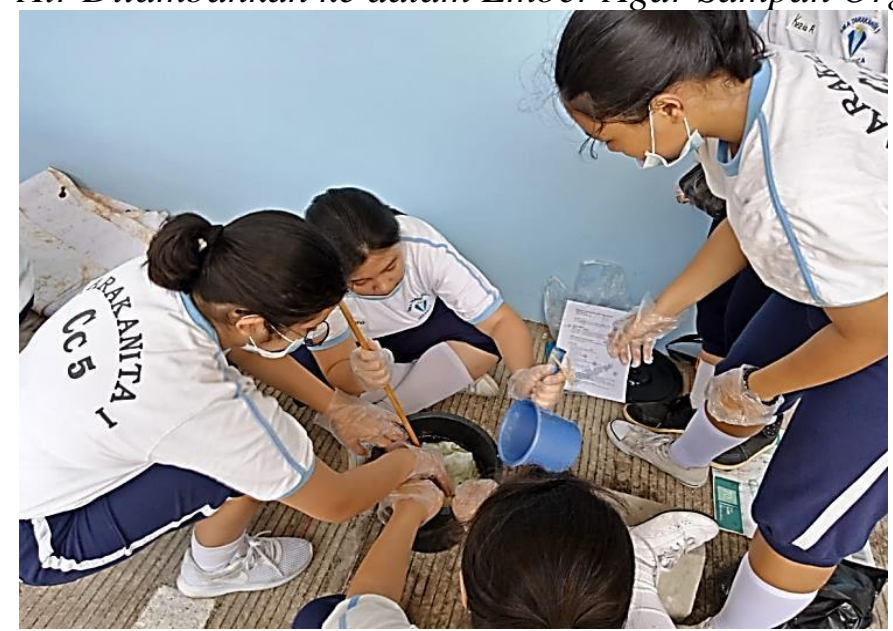




\section{Gambar 6.}

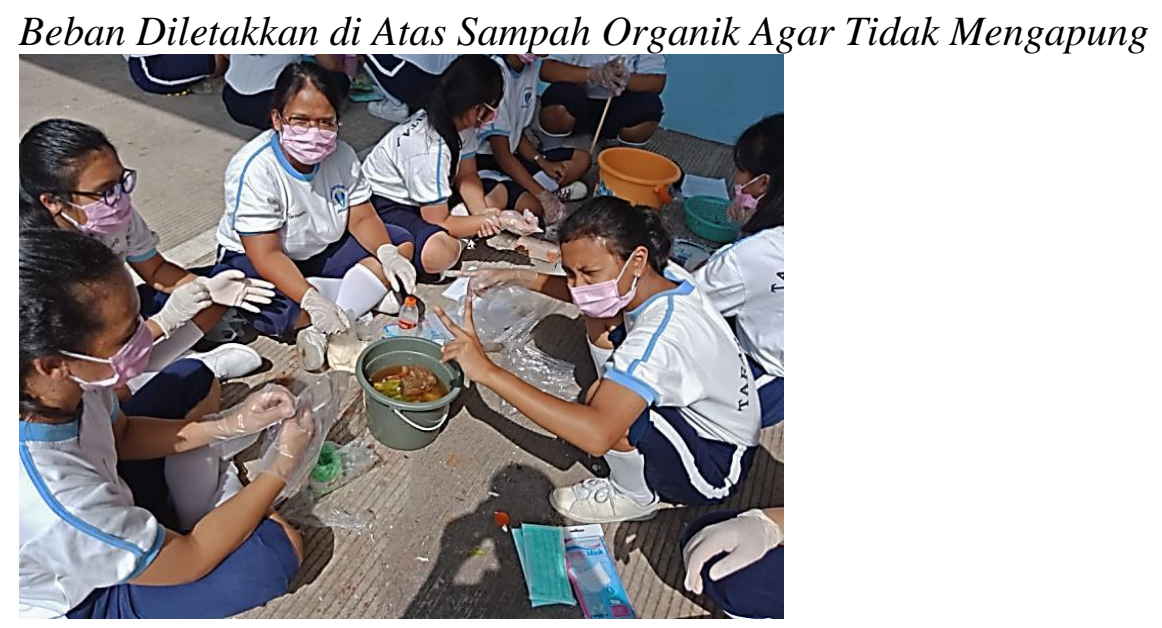

Setelah masa inkubasi selesai dan POC siap dipanen, penutup ember dibuka, kemudian karung berisi sampah sayur terfermentasi diangkat dan dipisahkan dari media cair. Sisa sampah organik padat lalu dapat dimanfaatkan lebih lanjut sebagai kompos. Hasil panen POC adalah media cair yang telah terfermentasi dan mengandung banyak mikroorganisme. Proses fermentasi yang berhasil ditandai dengan adanya bercak-bercak putih pada permukaan POC, sedangkan POC itu sendiri akan berwarna kuning kecoklatan dengan aroma menyengat. Bercak putih menunjukkan adanya aktivitas mikroorganisme pengurai sampah organik seperti Actinomycetes yang tumbuh pada permukaan POC (Sundari et al., 2012).

Hasil panen POC empat kelompok siswa dipaparkan dalam Tabel 2. Dari empat kelompok yang melaporkan hasil, tiga di antaranya memanen POC pada hari ke-15, dan satu kelompok lainnya memanen POC pada hari ke-21. Dari tiga kelompok yang memanen POC pada hari ke-15, terdapat satu kelompok yang menemukan belatung dalam ember tempat fermentasi sehingga POC tidak digunakan lebih lanjut untuk tanaman, sedangkan dua kelompok lainnya mengaplikasikan POC pada tanaman sawi dan palem dewasa, namun pengaruhnya terhadap pertumbuhan tanaman tidak ditentukan dalam kegiatan ini. Belatung yang ditemukan pada POC salah satu kelompok dapat berasal dari telur lalat yang telah ada pada sampah sayuran sebelum proses fermentasi dimulai. Selama fermentasi berlangsung, lalat tidak dapat masuk dan bertelur karena ember ditutup rapat. Fermentasi sampah organik secara anaerob dengan media cair memungkinkan pertumbuhan telur lalat menjadi belatung karena lingkungannya yang lembab dan kaya akan nutrisi. Keberadaan belatung yang masih hidup di saat panen menunjukkan bahwa proses fermentasi anaerob tidak berlangsung dengan baik. Jika fermentasi anaerob berlangsung dengan baik, belatung yang tumbuh di awal fermentasi lama-kelamaan akan mati karena kehabisan oksigen.

Sampah sayur yang difermentasi selama 21 hari nampak memberikan hasil POC yang lebih baik dibandingkan dengan sampah sayur yang difermentasi selama 15 hari. Hal ini menunjukkan bahwa periode fermentasi yang lebih panjang menghasilkan POC yang lebih matang. Proses konversi sampah organik secara anaerob yang sempurna pada umumnya berlangsung cukup lama, bahkan dapat membutuhkan waktu enam bulan hingga satu tahun (Himanen \& Hänninen, 2011; Mehta \& Sirari, 2018). Oleh sebab itu, waktu fermentasi POC dalam kegiatan ini diduga perlu diperpanjang untuk memperoleh kualitas POC yang lebih baik. Penambahan bioaktivator seperti EM4 dapat mempercepat proses fermentasi karena EM4 mengandung banyak jenis mikroorganisme seperti khamir, Actinomycetes, bakteri asam laktat (Lactobacillus sp., Streptomyces sp.), dan bakteri 
fotosintetik (Siboro et al., 2013). Aktivator EM4 telah terbukti membantu proses fermentasi sampah organik menjadi kompos maupun POC.

Salah satu kekurangan metode pembuatan pupuk organik secara anaerob adalah adanya bau busuk yang mengganggu. Pada proses degradasi sampah organik secara anaerob terjadi pembentukan gas berbau tak sedap seperti amonia dan hidrogen sulfida (Mwegoha, 2012). Apabila fermentasi berlangsung dengan baik dan sempurna, bau tidak sedap yang ditimbulkan saat proses berlangsung akan berangsur-angsur hilang (Nur et al., 2016). Pada kegiatan serupa di masa mendatang, rempah dengan kandungan minyak atsiri seperti sereh atau jahe dapat ditambahkan ke dalam POC untuk mengurangi bau tidak sedap yang timbul selama proses fermentasi anaerob (Nurhasanah \& Heryadi, 2013; Kusrinah et al., 2016).

Setelah POC dipanen dan dievaluasi, setiap kelompok siswa juga memberikan umpan balik kegiatan melalui kuesioner online evaluasi. Sebagian siswa menyatakan senang dan memperoleh pengetahuan serta pengalaman baru melalui kegiatan ini. Sebelumnya mereka hanya mengetahui bahwa sampah organik dapat diolah menjadi pupuk kompos padat saja. Setelah kegiatan ini, mereka mengetahui bahwa sampah organik juga dapat diolah dan dimanfaatkan kembali menjadi POC yang relatif mudah untuk dibuat. Namun sayangnya hampir semua POC yang dihasilkan masih berbau tak sedap, sehingga para peserta menilai bahwa pengolahan sampah organik menjadi kompos masih cenderung lebih mudah daripada pengolahannya menjadi POC.

\section{Tabel 2}

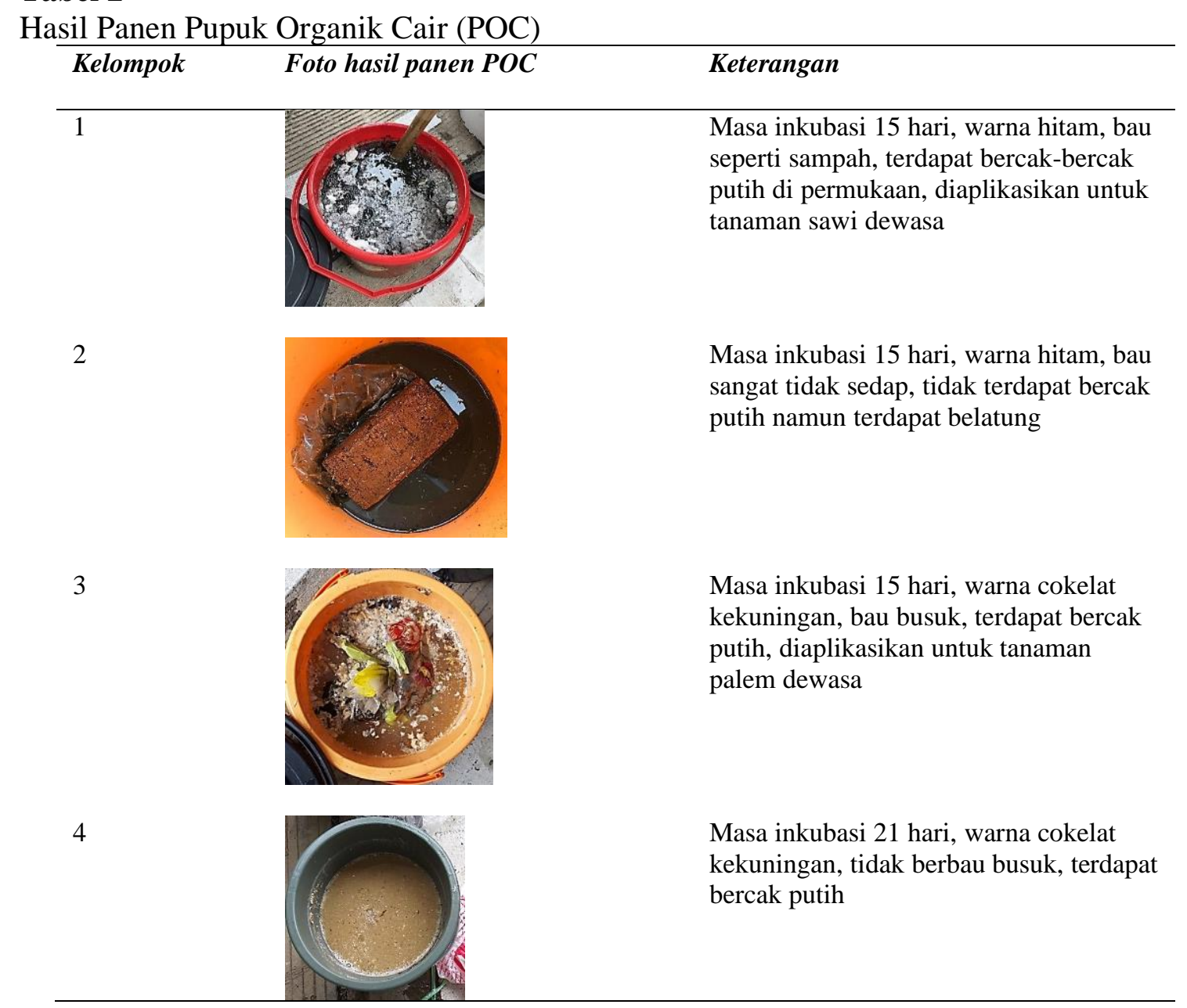




\section{KESIMPULAN DAN SARAN}

Kegiatan pengabdian masyarakat ini berguna untuk membangkitkan kesadaran remaja, khususnya siswa SMA terhadap pentingnya pengolahan sampah. Dengan adanya kegiatan ini, para siswa dapat mengetahui bahwa pengolahan dan pemanfaatan sampah organik menjadi POC relatif mudah dibuat.

Untuk pelaksanaan kegiatan serupa di masa yang akan datang, masa inkubasi/fermentasi sampah organik secara anaerob dapat diperpanjang. Selain itu, herbal seperti jahe atau sereh dapat ditambahkan ke dalam campuran untuk mengurangi bau yang timbul selama fermentasi anaerob. Kegiatan serupa juga dapat diintegrasikan dengan beberapa kegiatan sekolah dalam kerangka kerja sama untuk pembinaan siswa. Selain itu, kombinasi kegiatan pengolahan sampah organik menjadi kompos atau POC, dan sampah anorganik menjadi kreasi kerajinan tangan akan lebih menarik bagi para siswa untuk dilakukan di sekolah.

\section{Ucapan Terima Kasih}

Penulis mengucapkan terima kasih pada SMU Tarakanita 1 Jakarta dan Universitas Katolik Indonesia Atma Jaya yang telah menginisiasi kegiatan dan memberikan kesempatan pada tim pengabdi/penulis untuk berpartisipasi.

\section{REFERENSI}

BPS Indonesia. (2017) Statistik lingkungan hidup Indonesia 2017. Badan Pusat Statistik. https://www.bps.go.id/publication/2017/12/21/4acfbaac0328ddfcf8250475/statistiklingkungan-hidup-indonesia-2017.html.

Garnesia, I. (2018, Februari 2018). Mengintip kota-kota gudang sampah di Indonesia. Tirto.id. https://tirto.id/mengintip-kota-kota-gudang-sampah-di-indonesia-cE4o.

Himanen, M. \& Hänninen, K. (2011). Composting of bio-waste, aerobic and anaerobic sludgeseffect of feedstock on the process and quality of compost. Bioresource Technology, 102(3), 2842-2852. https://doi.org/10.1016/j.biortech.2010.10.059.

Kusrinah, K. Nurhayati, A., \& Hayati, N. (2016). Pelatihan dan pendampingan pemanfaatan eceng gondok (Eichornia crassipes) menjadi pupuk kompos cair untuk mengurangi pencemaran air dan meningkatkan ekonomi masyarakat Desa Karangkimpul Kelurahan Kaligawe Kecamatan Gayamsari Kotamadya Semarang. Dimas: Jurnal Pemikiran Agama untuk Pemberdayaan, 16(1), 27-48. https://doi.org/10.21580/dms.2016.161.890.

Means, N. E., Starbuck, C. J., Kremer R. J., \& Jett, L. W. (2005). Effects of a food waste-based soil conditioner on soil properties and plant growth. Compost Science and Utilization, 13(2), 116-121. https://doi.org/10.1080/1065657x.2005.10702227.

Mehta, C. M. \& Sirari, K. (2018). Comparative study of aerobic and anaerobic composting for better understanding of organic waste management: A mini review. Plant Archives, 18(1), 4448.

Mwegoha, W. (2012). Anaerobic composting of pyrethrum waste with and without effective microorganisms. African Journal of Environmental Science and Technology, 6(8), 293-299. https://doi.org/10.5897/ajest12.030.

Nur, T., Noor, A. R., \&, Elma, M. (2016). Pembuatan pupuk organik cair dari sampah organik rumah tangga dengan penambahan bioaktivator EM4 (Effective Microorganisms). Konversi, 5(2), 5-12. https://doi.org/10.20527/k.v5i2.4766.

Nurhasanah \& Heryadi, H. (2013). Pemanfaatan sereh (Cymbopogon cytratus) dalam menurunkan bau pada pupuk organik cair dan potensinya dalam meningkatkan produksi tanaman cabai (Capsicum annum). Jurnal Matematika, Sains, dan Teknologi, 14(1), 37-47. 
Siboro, E. S., Surya, E., \& Herlina, N. (2013). Pembuatan pupuk cair dan biogas dari campuran limbah sayuran. Jurnal Teknik Kimia USU, 2(3), 40-43. https://doi.org/10.32734/jtk.v2i3.1448.

Stabnikova, O., Ding, H. B., Tay, J.-H., \& Wang, J.-Y. (2005). Biotechnology for aerobic conversion of food waste into organic fertilizer. Waste Management and Research, 23(1), 3947. https://doi.org/10.1177/0734242x05049768.

Sundari, E., Ellysta, S., \& Rinaldo, R. (2012). Pembuatan pupuk organik cair menggunakan bioaktivator biosca dan EM4. Prosiding SNTK KOPI, 94-97. Indonesia.

Varma, V. S. \& Kalamdhad, A. S. (2014). Effects of leachate during vegetable waste composting using rotary drum composter. Sustainable Environment Research, 24(4), 245-256. https://doi.org/10.4491/eer.2014.19.1.067.

Warjoto, R. E., Hartanti, A. T., \& Canti, M. (2018). Metode komposting Takakura untuk pengolahan sampah organik rumah tangga di Cisauk, Tangerang. Jurnal Perkotaan, 10(2), 76-90. https://doi.org/10.25170/perkotaan.v10i2.306. 